\title{
RECENT DEVELOPMENTS IN PSYCHOSOCIAL INTERVENTIONS FOR PEOPLE WITH PSYCHOSIS
}

\section{Eddie McCann, MSc, RMN, DPSN (Thorn), CertEd.}

St. Bartholomew School of Nursing and Midwifery,

City University, London, United Kingdom

The advent of drug treatments for psychotic illness in the 1950 s, along with changes in social policy, heralded the move from institutionalized care to community care. Over the last decade, there have been research developments in the use of psychological techniques to manage psychotic symptomatology, particularly in the realms of cognitive behavioral therapies. There is growing evidence to suggest that psychological treatments can offer an adjunct or even an alternative to traditional medical treatments for patients with schizophrenia and other serious mental illnesses. Opportunities have arisen for mental health nurses to learn these new approaches to caring for people with enduring mental illnesses. The impact of psychological interventions in the treatment of psychosis and the implications for mental health nursing practice are discussed.

Schizophrenia is normally treated with neuroleptic drugs and although $70 \%$ of patients show improvement in psychotic symptomatology, many still experience distressing and recurrent symptoms (Curson, Patel, \& Liddle, 1988). In a community survey by Harrow and Silverstein (1977), 47\% of patients continued to experience persistent psychotic symptoms despite conventional neuroleptic drugs. The newer atypical antipsychotic medications (e.g., clozapine, olanzepine, risperidone) appear to have less extrapyramidal symptoms (Gerlach \& Peacock, 1995).

Address correspondence to Eddie McCann, City University, St. Bartholomew School of Nursing and Midwifery, Philpot Street, Whitechapel, London E1 2EA, UK. E-mail: E.J.P. McCann@city.ac.uk 
However, they still carry the risk of unwanted effects such as sedation, dysphoria, sexual dysfunction, weight gain, endocrine effects, autonomic and cardiovascular effects, anticholonergic effects, and seizures, as well as extrapyramidal problems (Barnes \& McPhillips, 1999). As a result, patients may be reluctant to accept drug treatments and some may even wish to cease taking medications altogether.

Treating a person with a psychosis can be extremely complex due to the range of difficulties, disorders and handicaps associated with the illness. Many patients have deficits in attention, concentration, short-term memory, motivation, planning, decision-making, and sense of pleasure (Sharma, 1999). Problems with unemployment, social isolation, service and family dependency abound. There may also be chronic disabilities related to self-care, socialization and work capacity (Haddock \& Tarrier, 1998). Other problems encountered by people with psychotic illness include depression, anxiety, and suicide. Kane and McGlashan (1995) propose that in order to address the heterogeneity of schizophrenia, a system of care is required, which includes pharmacological and psychosocial treatment approaches, that is, a biopsychosocial paradigm that attempts to be all-encompassing .

\section{EARLY APPROACHES}

Early work in the management of psychotic symptom s began with token economies in psychiatric hospitals using operant learning theories to modify behaviors through rewards and punishments. Tarrier (1992) suggests that changes in patients' overt behavior did not mean that there was a corresponding reduction in psychotic symptomatology. Patients may merely have learned to suppress symptoms and respond in more socially acceptable ways. Social skills training has been used to help people learn to cope with interpersonal relationships and includes interpersonal communication and community living skills. However, no research demonstrated the effect of social skills methods on relapse or the impact on the person once in the community. A lack of positive reinforcers at home may have contributed to the lack of success of social skills training and an in vivo training program was recommended (Halford \& Hayes, 1992).

\section{NEWER TREATMENTS}

Psychosocial treatments for schizophrenia take many shapes and all rely on interpersonal interaction for therapeutic gain (Birchwood \& 
Tarrier, 1992). The broad aims of these approaches work at increasing social functioning, decreasing distress, and reducing hospital admission rates through the provision of evidence-based psychosocial intervention s (Tarrier \& Birchwood, 1995).

This new wave of psychological treatment approaches that have developed in the last decade targets people with enduring mental health needs. Researchers have begun to look at cognitive behavioral interventions aimed at decreasing drug resistant psychotic symptoms; psychoeducation for patients and carers to monitor prodromal signs to ease early intervention; methods to facilitate medication compliance; and family interventions aimed at reducing relapse. Cognitive behavioral therapy is a structure d and time limited approach and can be used in the management of psychosis. It has three main goals: to reduce the distress and disability associated with residual psychotic symptomatology; to reduce emotional disturbance; and to promote the active participation of the individual in the prevention of relapse and social disability (Fowler, Garety, \& Kuipers, 1995; Nelson, 1997).

\section{TREATMENT OF AUDITORY HALLUCINATIONS}

Reduction of hallucinations has been accomplished through three methods: distraction techniques, focusing techniques, and anxiety reduction.

Distraction techniques that focus on the relationship between external stimuli and internal thought processes have been studied. Nelson, Thrasher, and Barnes (1991) tested the efficacy of earplugs, personal stereos, and vocalization tasks. The 'Walkman' had the greatest effect on reducing hallucinations. The vocalization tasks were least popular.

Focusing techniques are illustrate $d$ in the Bentall, Haddock, and Slade (1994) study. This study used a model that viewed hallucinatory experiences as occuring when patients fail to attribute internal mental events to themselves and instead attribute their presence to external factors. Patients who focused on their voices were asked to note form, loudness, tone, accent, and gender. Participants were asked to focus on the content and the related thoughts and assumptions of the voices. Three out of six subjects in this study had reductions in their voices' duration and associated distress.

Slade (1972) provides an example of anxiety reduction techniques when he examined antecedents and consequences of auditory hallucinations in anxiety-provoking situations. Systematic desensitization was used and a reduction in anxiety led to a decrease in hallucinations. Tarrier et al. (1988) showed that symptoms increased with higher levels of 
physiological arousal. The development of coping strategies for controlling this arousal should lead to a reduction in psychotic symptoms.

\section{DELUSIONAL BELIEFS}

Cognitive therapy has been generally used in the treatment of anxiety and depression. The same techniques are employed to challenge the evidence supporting delusional beliefs rather than confronting the beliefs themselves. Interventions are designed to modify reasoning processes that enhance coping strategies, which will reduce delusional beliefs (Bentall, 1994).

Chadwick and Lowe (1990) proposed that delusional beliefs can be maintained by the descriptions or rules people formulate to describe themselves and their interactions with others. They challenged beliefs and gave clients alternative rules with which to organize behavior. Results showed a reduction in conviction and preoccupation, and benefits were generalized across beliefs. Additional assessments demonstrated that there was no evidence of increased depression following intervention and benefits were maintained at six months follow-up. Similar findings were shown in a study by Kuipers et al. (1997).

\section{COPING STRATEGY ENHANCEMENT}

Many patients try to use a range of psychological or behavioral methods to cope with their symptoms (Tarrier, Harwood, Yusopoff, Beckett, \& Baker, 1990). The therapist carries out a detailed behavioral assessment to identify which coping strategies the patient uses most successfully. The patient is then trained to make the most use of these strategies to control symptoms.

Tarrier et al. (1993) compared two cognitive behavioral approaches, coping strategy enhancement and problem-solving, in a group of 27 patients experiencing hallucination $\mathrm{s}$ and delusions. Both treatments significantly reduced anxiety and delusion s compared to a control group, with coping strategy enhancement showing more improvement over problemsolving. In a larger randomized control study involving 72 chronic schizophrenic patients (Tarrier et al., 1998), coping strategy enhancement was combined with problem-solving and relapse prevention. This was compared with two controls: a supportive counseling control and a treatment as usual control. The combined treatments were superior to the supportive counseling, which in turn was significantly better than treatment as usual. 


\section{MONITORING PRODROMAL SIGNS}

Researchers have looked at the identification of early warning signs that precede a relapse. These forewarnings are characterized by nonpsychotic symptoms including mild depression or dysphoria, anxiety, and interpersonal sensitivity. Low level psychotic symptoms may include suspiciousness, ideas of reference, and feelings of not fitting in with others (Hirch \& Jolley, 1989). Birchwood et al. (1989) showed that $72 \%$ of patients had a prodrome of at least two weeks and $59 \%$ had a prodrome of four weeks or more. Hertz and Melville (1980) found $70 \%$ of patients and $93 \%$ of relatives reported changes that indicated that a relapse was imminent. Frequent monitoring of symptoms and behaviors facilitates the identification of early signs of relapse. Furthermore, early intervention can reduce the probability of relapse by intensifying treatment (e.g., neuroleptic medications), providing greater psychological support, and increased use of cognitive behavioral techniques. If prodromes or 'personal relapse signatures' are identified, preventative strategies can be incorporated into the care planning system.

\section{MEDICATION COMPLIANCE}

An important factor in prolonged psychosis and the occurrence of relapse is noncompliance with neuroleptic medication. According to Vaughn and Leff (1976), patients who refused drugs for one month out of a nine-month follow-up period had about three times the relapse rate of those who were compliant.

More recently, therapeutic approaches have been used to increase compliance. Eckman and Liberman (1990) examined education and the nature of side effects, emphasizing the teaching of skills such as memory aids with noncompliant patients.

Kemp, Hayward, and Applewhaite (1996) have adapted the theory and practice of motivational interviewing from the substance abuse literature and applied it to compliance enhancement in schizophrenia. This cognitive behavioral approach encourages the patient to explore the pros and cons of continuing or discontinuin g medication. A randomized controlled trial of 4-6 sessions of motivational interviewing compared with a control condition of nonspecific counseling, was conducted with 47 acute psychotic patients. There was a significant improvement in compliance, global functioning, and attitudes to treatment in the experimental group. 


\section{FAMILY INTERVENTIONS}

Another cognitive behavioral approach is family interventions. This model consists of education regarding the illness, and its treatment, management, and prognosis. It also includes strategies to reduce stress in the family, increase independence, and to encourage problem-solving (Barrowclough \& Tarrier, 1992; Kuipers, Leff, \& Lam, 1992). Educating families about 'expressed emotion' (EE) may be a vital component of family interventions. Brown and Rutter (1966) were the first researchers to look at expressed emotion. A high EE environment is characterized by relative s who show high levels of criticism, hostility, and emotional overinvolvement. Several studies have shown that patients living in high EE environments have much higher relapse rates than those in low EE situations (Kavanagh, 1992). Vaughn and Leff (1976) found that patients who were not taking medication and spent more than 35 hours per week with their high EE relative had a high relapse rate over nine months $(92 \%)$. Those with less contact and who were taking medication showed a low relapse rate $(15 \%)$. In low EE environments, the relapse rate did not relate to whether patients were taking medications or not. Tarrier et al. (1988) suggested that family intervention s for patients with schizophrenia could reduce relapse rates, increase social functioning, and reduce subjective burden in their families. Follow-up studies have shown the benefits of interventions after eight years (Tarrier et al., 1994). Patients receiving family intervention also demonstrated greater medication compliance and lower admission rates (De Jesus Mari \& Streiner, 1994).

\section{IMPLICATIONS FOR NURSING PRACTICE}

The research cited suggests that psychological interventions for people with serious mental illness can have a great impact on relapse rates, psychotic symptoms, length of hospital stay, affective symptoms, and the social functioning of the patient and care giver. Despite research supporting the efficacy of psychological approaches, they have not become routine in clinical practice.

In the UK, The Thorn Nurse Initiative, a diplom a program that teaches community mental health practitioners the skills of case management, cognitive behavioral intervention, and schizophrenia family management, has been researched (Lancashire et al., 1997). Patients receiving Thorn psychosocial intervention s showed a significant reduction in positive, negative, and affective symptoms, together with an improvement in social functioning. In contrast, Brooker et al. (1994) studied patients receiving standard psychiatric nursing care and showed that no 
significant changes in symptoms or social functioning were evident. Despite these findings, Thorn practitioners generally find it difficult to continue using their specialist skills due to lack of support in the workplace and weaknesses in the service infrastructure needed to put their practices into operation.

In Australia, however, a pioneering service has been developed to work with people who experience psychosis. The Early Psychosis Prevention and Intervention Centre (EPPIC) was established in 1992 and employs mental health specialists devoted to providing a range of preventative intervention s for psychotic disorders. The main aims of the project include a reduction in the duration of untreated psychosis; expert treatment of the first episode of psychosis; reduction of the duration of active psychosis in the first episode and beyond; and maximized recovery, reintegration, and quality of life (McGorry et al., 1996). Advancements have been made in Cognitive Psychotherapy for Early Psychosis (COPE). This is a dedicated service for young people with emerging psychotic illness. The emphasis is on early, intensive, and integrated biological, psychological, and social intervention s in the two years after the onset of treatment. The present emphasis on community care and the closure of mental hospitals places a burden on families, care givers, and services. The reorganization of fragmented services alone is not sufficient for the success of community living. Mental health nurses trained to deliver psychosocial interventions need recognition and strong organizational backing. Otherwise, attempts to implement these therapeutic techniques will remain futile. Further developments of innovative psychological and psychosocial management methods are crucial if caring for chronically ill people in the community is to be effective. Of course, quality services need investment. Community care can have positive benefits for people with long-term and enduring mental health problems, but only if carried out appropriately and with rigour.

\section{REFERENCES}

Barnes, T. R. E., \& McPhillips, M. A. (1999). Critical analysis and comparison of the side-effect and safety profiles of new antipsychotics. British Journal of Psychiatry, 174(suppl. 38), 38-43.

Barrowclough, C., \& Tarrier, N. (1992) Families of schizophrenic patients: Cognitive behavioural interventions. London: Chapman \& Hall.

Bentall, R. P. (1994). Cognitive biases and abnormal beliefs: Towards a model of persecutory delusions, pp. 159-174. In A. S. David \& J. Cutting (Eds.), The neuropsychology of schizophrenia. London: Erlbaum.

Bentall, R. P., Haddock, G., \& Slade, P. (1994). Cognitive-behaviour therapy for persistent auditory hallucinations: From theory to therapy. Behaviour Therapy, 25, 51-66. 
Birchwood, M., Smith, J., Macmillan, F., Hogg, B., Prasad, R., Harvey, C., \& Bering, S. (1989). Predicting relapse in schizophrenia: The development of an early signs monitoring system using patients and families as observers: A preliminary investigation. Psychological Medicine, 19, 649-656.

Birchwood, M., \& Tarrier, N. (1992). Innovations in the psychological management of schizophrenia. Chichester, UK: Wiley.

Brooker, C., Falloon, I., Butterworth, A., Goldberg, D., Graham-Hole, V., \& Hillier, V. (1994). The outcome of training community psychiatric nurses to deliver psychosocial interventions. British Journal of Psychiatry, 165, 222-230.

Brown, G. W., \& Rutter, M. (1966). The measurement of family activities and relationships: A methodological study. Human Relations, 19, 241-263.

Chadwick, P. D., \& Lowe, C. F. (1990). The measurement and modification of delusional beliefs. Journal of Consulting and Clinical Psychology, 58, 225-232.

Curson, D. A., Patel, M., \& Liddle, P. F. (1988). Psychiatric morbidity of a long-stay hospital population with chronic schizophrenia and implications for future community care. British Medical Journal, 297, 819-822.

De Jesus Mari, J., \& Streiner, D. L. (1994). An overview of family interventions and relapse in schizophrenia: Meta-analysis of research findings. Psychological Medicine, 24, 565-578.

Eckman, T. A., \& Liberman, R. P. (1990). A large-scale field test of a medication management program for people with schizophrenia. Psychosocial Rehabilitation Journal, 13, 31-35.

Fowler, D., Garety, P., \& Kuipers, E. (1995). Cognitive behaviour therapy for psychosis. Chichester, UK: Wiley.

Gerlach, J., \& Peacock, L. (1995). Intolerance to neuroleptic drugs: The art of avoiding extrapyramidal syndromes. European Psychiatry, 10(suppl. 1), 27-31.

Haddock, G., \& Tarrier, N. (1998). Assessment and formulation in the cognitive behavioural treatment of psychosis. In N. Tarrier, A. Wells, \& G. Haddock (Eds.), Treating complex cases: The cognitive behavioural therapy approach. Chichester: Wiley.

Halford, W., \& Hayes, R. (1992). Social skills training with schizophrenic patients. In D. Kavanagh (Ed.), pp. 254-274. Schizophrenia. An overview and practical handbook. London: Chapman and Hall.

Harrow, M., \& Silverstein, M. (1977). Psychotic symptoms in schizophrenia after the acute phase. Schizophrenia Bulletin, 3, 608-616.

Hertz, M., \& Melville, C. (1980). Relapse in schizophrenia. American Journal of Psychiatry, 137, 801-805.

Hirch, S. R., \& Jolley, A. G. (1989). The dysphoric syndrome in schizophrenia and its implications for relapse. British Journal of Psychiatry (suppl. 5), 46-50.

Kane, J. M., \& McGlashan, T. H. (1995). Treatment of schizophrenia. The Lancet, 346, $820-825$.

Kavanagh, D. (1992). Recent developments in expressed emotion and schizophrenia. British Journal of Psychiatry, 160, 601-620.

Kemp, R., Hayward, R., \& Applewhaite, G. (1996). Compliance therapy in psychotic patients: A randomised control trial. British Medical Journal, 312, 345-349.

Kuipers, E., Garety, P., Fowler, D., Dunn, G., Bebbington, P., Freeman, D., \& Hadley, C. (1997). London-East Anglia randomised control trial of cognitive behavioural 
therapy for psychosis. I: Effects of the treatment phase. British Journal of Psychiatry, 171, 319-327.

Kuipers, E., Leff, J., \& Lam, D. (1992). Family work for schizophrenia. A practical guide. London: Gaskell.

Lancashire, S., Haddock, G., Tarrier, N., Baguley, I., Butterworth, A. C., \& Brooker, C. (1997). Effects of training in psychosocial interventions for community psychiatric nurses in England. Psychiatric Services, 48 (1), 39-41.

McGorry, P. D., Edwards, J., Mihalopoulos, C., Harrigan, S. M., \& Jackson, H. J. (1996). EPPIC. An evolving system of early detection and optimal management. Schizophrenia Bulletin, 22, 302-326.

Nelson, H. E. (1997). Cognitive behavioural therapy with schizophrenia: A practice manual. Cheltenham, UK: Stanley Thornes (Publishers) Ltd.

Nelson, H. E., Thrasher, S., \& Barnes, T. R. E. (1991). Practical ways of alleviating auditory hallucinations. British Medical Journal, 302, 327.

Sharma, T. (1999). Cognitive effects of conventional and atypical antipsychotics in schizophrenia. British Journal of Psychiatry, 174(suppl. 38), 44-51.

Slade, P. D. (1972). The effect of systematic desensitisation on auditory hallucinations. Behaviour Research Therapy, 10, 85-91.

Tarrier, N. (1992). Psychological treatment of positive schizophrenic symptoms. In D. J. Kavanagh (Ed.), pp. 356-373. Schizophrenia: An overview and practical handbook. Vol. 1. London: Chapman and Hall.

Tarrier, N., Barrowclough, C., Porceddu, K., \& Fitzpatrick, E. (1994). The Salford family intervention project: Relapse rates of schizophrenia at five and eight years. British Journal of Psychiatry, 165, 829-832.

Tarrier, N., Barrowclough, C., Vaughn, C., Bamrah, J. S., Porceddu, K., Watts, S., \& Freeman, H. (1988). The community management of schizophrenia: A controlled trial of behavioural intervention with families to reduce relapse. British Journal of Psychiatry, 153, 532-542.

Tarrier, N., Beckett, R., Harwood, S., Baker, A., Yusupoff, L., \& Ugarteburu, I. (1993). A trial of two cognitive behavioural methods of treating drug-resistant residual psychotic symptoms in schizophrenic patients. British Journal of Psychiatry, 162, 524532.

Tarrier, N., \& Birchwood, M. (Eds.). (1995). Psychological management of schizophrenia. Chichester, UK: Wiley.

Tarrier, N., Harwood, S., Yusopoff, L., Beckett, R., \& Baker, A. (1990). Coping Strategy Enhancement (CSE): A method of treating residual schizophrenic symptoms. Behavioural Psychotherapy, 18, 283-289.

Tarrier, N., Yusupoff, L., Kinney, C., McCarthy, E., Gledhill, A., Haddock, G., \& Morris, J. (1998). A randomised controlled trial of intensive cognitive behaviour therapy for chronic schizophrenia. British Medical Journal, 317, 303-307.

Vaughn, C. E., \& Leff, J. P. (1976). The influence of family life and social factors on the course of psychiatric illness. British Journal of Psychiatry, 129, 125-137. 